AVALIAÇÃO DA QUALIDADE DAS ÁGUAS DOS MANANCIAIS QUEE ABASTECEM A CIDADE DE SALVADOR (BA)

\title{
EVALUATION OF THE QUALITY OF MANANTIAL WATER SUPPLYING THE CITY OF SALVADOR (BA)
}

\author{
ALVES, Helena Maria Andrade ${ }^{1 *}$; YAMANAKA, Cristina Yassuko²; AZCONA Miguel Angel \\ Lobo3; BRASIL, Valter Alexandre"; GARCIA, Rui Jesus Lorenzo; MARTINS, Djavã de \\ Santana ${ }^{6}$; \\ 1,2,3,4,5,6 Secretaria de Ciência , Tecnologia e Inovação - CEPED- Centro de Pesquisas e Desenvolvimento km \\ zero da Rodovia BA-512, Camaçari - BA, Brasil \\ (fone: +55 713634 7314; fax: +55 713634 7389) \\ * Helena Maria Andrade Alves \\ e-mail: heandrade@ceped.ba.gov.br
}

\section{RESUMO}

Desde 2011, o Centro de Pesquisas e Desenvolvimento - CEPED realiza atividades de amostragem e análise das águas dos mananciais que abastecem a cidade de Salvador para avaliar o Índice de Qualidade da Água (IQA). O IQA é um importante indicador da relação entre uso e ocupação do solo e qualidade da água em uma bacia hidrográfica. A finalidade do presente trabalho é apresentar um estudo da qualidade das águas dos rios Paraguaçu, Joanes, Jacuípe e Ipitanga, que são responsáveis pelo abastecimento de água para a população da região metropolitana de Salvador com mais de três milhões de habitantes e maior densidade demográfica do Norte Nordeste. Através desse estudo pode-se concluir que há diminuição da qualidade das águas nos pontos próximos de áreas urbanizadas devido a falta de esgotamento sanitário, bem como nas áreas onde há comprometimento da cobertura vegetal ciliar.

Palavras-chave:Monitoramento, rios, IQA, Bahia.

\section{ABSTRACT}

Since 2011, the Centro de Pesquisas e Desenvolvimento - CEPED performs sampling and analysis activities of the waters of the springs that supply the city of Salvador to assess the Water Quality Index (WQI). The WQI is an important indicator of the relationship between use and land cover and water quality in a watershed. The purpose of this paper is to present a study of water quality of rivers Paraguaçu, Joanes, Jacuípe, Ipitanga, which are responsible for the water supply for the population of metropolitan region of Salvador with more than three million inhabitants and highest population density Northeast North. Through this study we can conclude that there is a decrease in water quality in nearby points of urbanized areas due to lack of sanitation, as well as in areas where there is impairment of riparian vegetation cover.

Keywords: Monitoring, rivers, WQI, Bahia. 


\section{INTRODUÇÃO}

A ação humana sobre os ambientes aquáticos vem alterando drasticamente a qualidade das águas, pois estes são suscetíveis às substâncias químicas lançadas principalmente nas proximidades de áreas urbanas, afetando os organismos que se desenvolvem neste meio. $O$ termo qualidade da água não se refere a um estado de pureza, mas, as características físicas, químicas e biológicas que determinam as diferentes finalidades para o uso da água. Dentre os vários usos da água doce, destacam-se aqueles empregados para abastecimento humano e industrial, higiene pessoal e doméstica, irrigação, geração de energia elétrica, navegação, preservação da flora e fauna, aquicultura e recreação. Desses usos, o abastecimento humano é considerado prioritário (Freitas, 2000).

A qualidade de determinada água se dá em função dos processos de ocupação em uma bacia hidrográfica, sendo modificada por diversos fatores atuantes (Braga et al., 2005). Assim, a retirada da cobertura vegetal ciliar de riachos, a intensa implementação da agropecuária e o lançamento de efluentes domésticos tem acarretado em interferências diversas nos padrões de qualidade dos corpos d'água (Faria e Cavinatto, 2000; Gergel et al., 2002). Com isto, são necessários mecanismos que viabilize uma avaliação nos padrões dos corpos d'água regionais e determinação de sua qualidade.

A manutenção da qualidade das águas é importante para o equilíbrio aquático e para o abastecimento da população. Associado as mudanças climáticas e a segurança alimentar, a qualidade da água é um dos maiores desafios do século XXI. No fórum econômico mundial em dos seus relatórios "riscos globais 2012", a água aparece como um dos cinco principais riscos para a saúde social, econômica e ambiental (The Royal AcademyofEngineering, 2012).

Uma das formas de se avaliar a qualidade da água de um corpo hídrico é através da adoção de índices da qualidade da água que podem avaliar uma série de parâmetros analisados num único número, facilitando a interpretação de extensas listas de parâmetros ou indicadores, possibilitando a classificação da qualidade da água. $O$ índice de qualidade da água é um número adimensional que exprime a qualidade da água para os diversos usos. Esse número é obtido da junção de dados físico- químicos, bacteriológicos e químicos através de metodologias específicas. Esses índices podem ser usados como ferramenta da interpretação de dados, auxiliando na avaliação dos resultados encontrados, representando a qualidade da água numa determinada escala que propiciam meios de julgar os controles ambientais estabelecidos, proporcionando uma idéia geral da evolução da qualidade do manancial ao longo do tempo e também permitindo uma comparação entre diferentes mananciais.

\section{DESENVOLVIMENTO OU MATERIAL E MÉTODOS OU PARTE EXPERIMENTAL}

\section{1 Área de Estudo}

A água que abastece a região metropolitana de Salvador é procedente da Barragem de Pedra do Cavalo, no Rio Paraguaçu, e dos rios Joanes (barragens Joanes I e II), Jacuípe (barragem de Santa Helena) e Ipitanga (barragens Ipitanga I, II e III), localizados na Região Metropolitana de Salvador (Figura 1).

\subsection{Localização dos pontos de amostragem}

Os pontos escolhidos para 0 monitoramento da qualidade da água estão localizados nas proximidades dos pontos de captação da Empresa Baiana de Águas e Saneamento - EMBASA. A Figura 1 apresenta a distribuição espacial dos pontos de amostragem, cuja identificação encontra-se descrita nas tabela 1 e tabela 4.

\subsection{Amostragem e ensaio laboratorial}

As amostras utilizadas neste trabalho foram coletadas no período de julho de 2011 a junho de 2014 quadrimestralmente, conforme o Guia nacional de coleta e preservação de amostras, publicado pela Agência Nacional de Águas (ANA, 2011). Os ensaios realizados foram: temperatura, turbidez, $\mathrm{pH}$, fósforo total, nitrogênio total, oxigênio dissolvido, demanda bioquímica de oxigênio, sólidos totais e coliformes termotolerantes. Os procedimentos analíticos foram executados conforme as normas descritas no Standard Methods for theExaminationofWaterandWastwater(SMEWW, 2012). Foram analisadas 95 amostras, totalizando 855 determinações. 


\subsection{Cálculo do Índice de Qualidade da Água}

O cálculo do Índice de Qualidade da Água - IQA foi determinado através da metodologia adaptada e desenvolvida pela Companhia de Tecnologia de Saneamento Ambiental - CETESB a partir do modelo original da "NationalSanitation Foundation" dos Estados Unidos -NSF(Eq. 1 e Eq. 2).

A Tabela 2 apresenta os parâmetros utilizados na determinação do IQA com os respectivos pesos.

Tabela 2. Parâmetros para o cálculo do IQA

\begin{tabular}{l|c}
\hline PARÂMETRO & PESO \\
\hline Oxigênio dissolvido (\% OD) & 0,17 \\
Coliformes Termotolerantes (NMP) & 0,15 \\
Potencial Hidrogeniônico & 0,12 \\
Demanda Bioquímica de Oxigênio & 0,10 \\
Nitrogênio Total (mg/L) & 0,10 \\
Fósforo Total (mg/L) & 0,10 \\
Temperatura (ํㅡ) & 0,10 \\
Turbidez (NTU) & 0,08 \\
Sólidos Totais (mg/L) & 0,08 \\
\hline
\end{tabular}

$$
I Q A=\prod_{i=1}^{n} q_{i}^{w i}
$$

Onde:

IQA: Î́ndice de Qualidade das Águas, um número entre 0 e 100;

qi: qualidade do i-ésimo parâmetro, um número entre 0 e 100;

wi: peso correspondente ao i-ésimo parâmetro, um número entre 0 e 1, atribuído em função da sua importância para a conformação global de qualidade, conforme a equação 2 .

$$
\sum_{i=1}^{n} w i=1
$$

Em que:

n: número de parâmetros que entram no cálculo do IQA.

A partir do cálculo efetuado, determinouse a qualidade das águas, que é indicada pelo $I Q A$, variando numa escala de 0 a 100, conforme tabela 3.
Tabela 3. Classificação da Qualidade da Água

\begin{tabular}{l|l}
\hline Nível de Qualidade & Faixa \\
\hline Excelente & $79<\mathrm{IQA}<100$ \\
Bom & $51<\mathrm{IQA}<79$ \\
Médio & $36<\mathrm{IQA}<51$ \\
Ruim & $19<\mathrm{IQA}<36$ \\
Péssimo & $\mathrm{IQA}<19$ \\
\hline
\end{tabular}

\section{RESULTADOS E DISCUSSÃO}

A tabela 4 e a figura 2 apresentam os resultados para o Índice de Qualidade da Água dos rios Paraguaçu, Joanes, Jacuípe e Ipitanga.

Tabela 4. Localização dos pontos de amostragens e valores do IQA.

\begin{tabular}{c|l|c|c|c}
\cline { 3 - 5 } \multicolumn{2}{c}{} & \multicolumn{3}{c}{ IQA } \\
\hline & $\begin{array}{c}\text { Ponto de } \\
\text { amostragem }\end{array}$ & Mínimo & Máximo & Médio \\
\hline A & RCN-BIP-001 & 64,88 & 83,95 & 78,89 \\
B & RCN-BJN-001 & 59,12 & 83,77 & 74,77 \\
C & RCN-BSH-050 & 50,06 & 70,33 & 59,24 \\
D & RCN-BSH-003 & 63,58 & 83,66 & 73,41 \\
E & RCN-BSH-001 & 66,94 & 84,92 & 79,86 \\
F & RCN-BJO-001 & 68,15 & 84,55 & 78,69 \\
G & RCN-BJO-004 & 70,19 & 82,54 & 76,80 \\
H & PRG-BCV-001 & 62,64 & 82,68 & 73,43 \\
I & PRG-BCV-002 & 66,15 & 82,94 & 75,02 \\
J & PRG-BCV-003 & 63,82 & 83,52 & 75,19 \\
K & PRG-BCV-004 & 72,58 & 82,16 & 78,26 \\
1 & PRG-JCP-600 & 37,97 & 59,57 & 47,50 \\
2 & PRG-PRG-600 & 55,08 & 75,38 & 69,69 \\
\hline \multicolumn{4}{|c}{}
\end{tabular}

A avaliação do IQA nos pontos de amostragem do rio Paraguaçu $(\mathrm{H}, \mathrm{I}, \mathrm{J}$ e $\mathrm{K})$ demonstrou que todos os pontos apresentaram valores médios de IQA classificados como bom. Entretanto, no ponto H, o IQA mínimo de 62,64 deslocou a média para 73,43, valor este, inferior às demais médias deste manancial. Como forma de entender as atividades antrópicas sobre este manancial, foram introduzidos dois novos pontos de amostragem:O ponto 1 (tabela 4 e figura 3 ) localizado no Rio Jacuípe, afluente do rio Paraguaçu, apresentou IQA médio de 47,50 demonstrando a influência dos despejos dos esgotos sanitários oriundos da cidade de Feira de Santana, com população estimada de 600.000 habitantes.

O ponto 2, situado no rio Paraguaçu na 
confluência da BR 116 e da BR 242, apresentou IQA mínimo de 55,08, demonstrando indícios de desmatamento da mata ciliar, explicado pelos valores mais elevados de turbidez quando comparados com os pontos mais próximos da nascente deste rio.

Os pontos $\mathrm{C}, \mathrm{D}$ e $\mathrm{E}$, pertencentes ao rio Jacuípe que faz parte da Bacia do Recôncavo Norte, estão localizados na Barragem de Santa Helena e apresentam em média IQA bom. O ponto $\mathrm{C}$ apresentou o menor valor de IQA médio $(59,24)$, que apesar de ser classificado como bom demonstra a influência dos esgotamentos sanitários das cidades de Dias D'Ávila e Nova Dias D’Ávila sobre esse curso d'água.

Os rios Ipitanga (ponto $A$ ), Joanes $\mathrm{I} / \mathrm{II}$ (pontos B, F e G) apresentam IQA médio classificados como bom. A qualidade das águas está sendo preservada devido a uma iniciativa do governo estadual que 1999 através do decreto 7.596 de 05 de junho de 1999 criou a área de preservação ambiental de Joanes/lpitanga com objetivo de proteger as represas Joanes I e II e Ipitanga I, II e III, além do estuário do rio Joanes (Santos, 2010).

\section{CONCLUSÕES}

Os Índices de Qualidade da Água (IQA) dos mananciais que abastecem a região metropolitana de Salvador foram classificados como bom no período monitorado. Entretanto, medidas de caráter preventivas e corretivas, como conservação da mata ciliar, tratamento de esgotos sanitários e fiscalização de lançamentos de efluentes industriais, devem ser aplicadas de modo a minimizar os custos de tratamento de água e garantir a saúde da população.

\section{AGRADECIMENTOS}

Os autores agradecem ao SIBRATEC/RESAG pelo apoio financeiro e ao Instituto do Meio Ambiente e Recursos Hídricos INEMA pela parceria destes últimos anos.

\section{REFERÊNCIAS}

1. Freitas, A. J. Gestão de recursos hídricos. In: Silva, D. D. \&Pruski, F. F. (Eds.) Gestão de recursos hídricos:aspectos legais, econômicos, administrativos e legais. Brasília: Secretaria de Recursos Hídricos; Viçosa, MG: Universidade
Federal de Viçosa; Porto Alegre: Associação Brasileira de Recursos Hídricos, 659p. 2000.

2. Braga, B. et al. Introdução à engenharia ambiental. São Paulo: Pearson Prentice Hall, 2005.

3. Faria, B. V.; Cavinatto, V. As Bacias hidrográficas do Estado. In: EMPAER. Manual técnico de microbacias hidrográficas. Cuiabá, 339p. 2000.

4. Gergel,S.E.Landscape indicators of human impacts to riverine systems. Aquatic Science, v.64, p.118-128, 2002.

5. THE ROYAL ACADAMY OF ENGINEERING. Engineerig the future of water. Reviewof2011discussion series London, 2012.

6. GUIA NACIONAL DE COLETA E PRESERVAÇÃO DE AMOSTRAS. São Paulo: CETESB; Brasília: ANA, 2011.

7. APHA - Standard Methods for the Examination of Water and Wastewater, 22th ed. Washington, 2012

8. CETESB - Companhia Ambiental do Estado de São Paulo. http://www.cetesb.sp.gov.br (Acesso: em junho/2014).

9. INEMA - Instituto do Meio Ambiente e Recursos Hídricos. http://www.inema.ba.gov.br (Acesso: em maio/2014).

10. INEMA - Instituto do Meio Ambiente e Recursos Hídricos.Disponivel em: $<$ http://www.inema.ba.gov.br/wpcontent/uploads/2011/09/DECRETON\%C2\%BA-7.596-DE-05-DE-JUNHO-DE1999-Joanes-Ipitanga.pdf> (Acesso em: junho/2014).

11. AGÊNCIA NACIONAL DE ÁGUAS - ANA. 2009. Portal da Qualidade das Águas. Disponível em:<http://pnqa.ana.gov.br> (Acesso em: maio/2014).

12. Santos, E. et al. O Caminho das Águas em Salvador: Bacias Hidrográficas, Bairros e Fontes. Salvador: CIAGS/UFBA/SEMA, 2010; 486p.

13. CONSELHO NACIONAL DO MEIO AMBIENTE - CONAMA. 2005.Resolução Conama no 357/05: Dispõe sobre a classificação dos corpos de água e diretrizes ambientais para 0 seu enquadramento, bem como estabelece as condições e padrões de lançamento de efluentes, e dá outras providências.Brasília, 2005. Disponível 
em:<www.mma.conama.gov.br/conama>

(Acesso em:maio/2014).

14. GOVERNO DO ESTADO DO RIO DE JANEIRO; SECRETARIA DE ESTADO DO AMBIENTE; INSTITUTO ESTADUAL DO AMBIENTE. Qualidade da água; Disponível em:<http://www.inea.rj.gov.br/fma/qualida de-agua.asp> (Acesso em: junho/2014).

15. BAHIA. Empresa Baiana de Águas e Saneamento. História do abastecimento de água em Salvador. Salvador, 2003. 


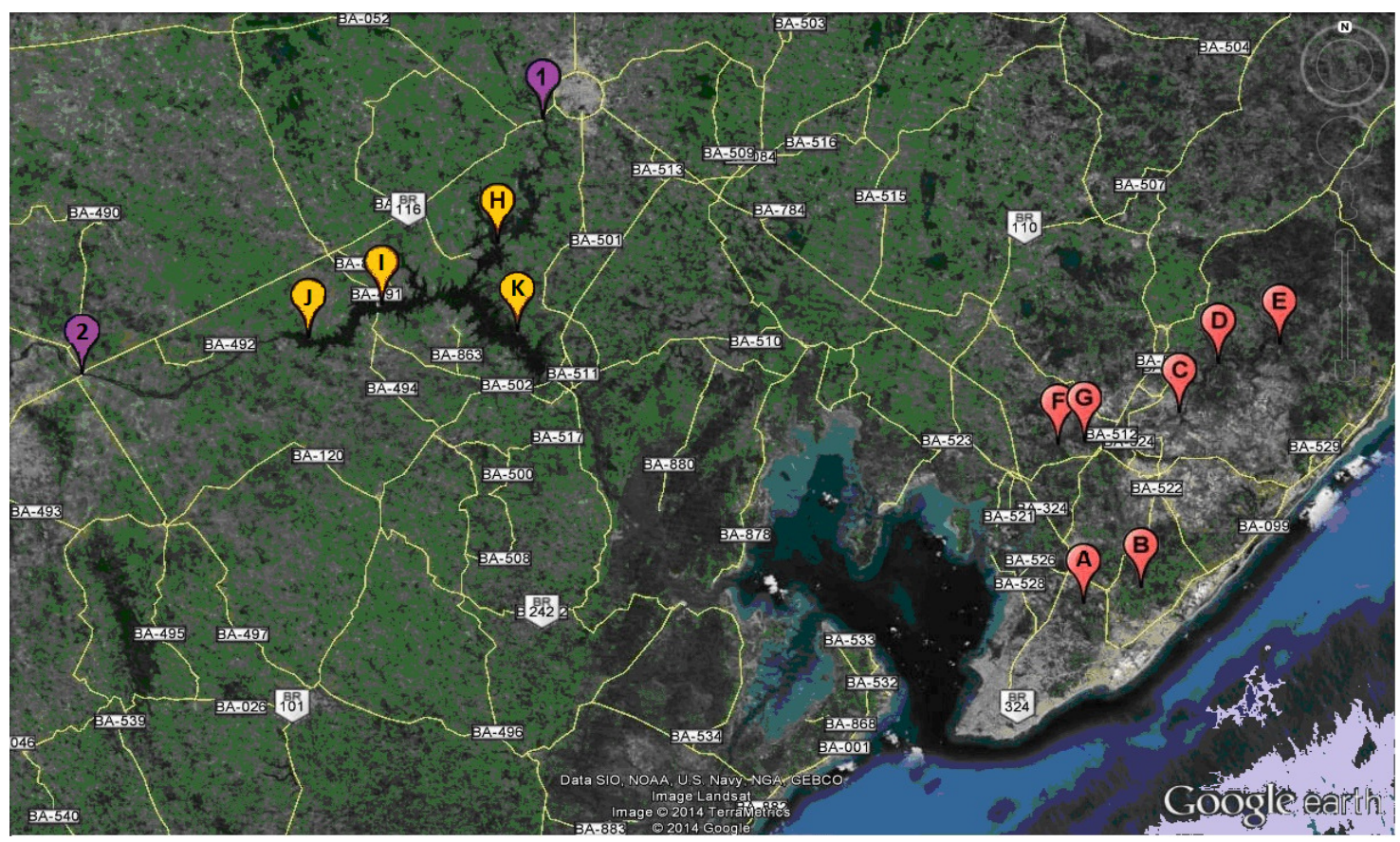

Figura 1.Mapa com os pontos de amostragem.

Fonte: Google Earth.

Tabela 1. Legenda dos pontos de amostragem.

\begin{tabular}{c|c|c|c}
\hline & Manancial & Longitude (W) & Latitude (S) \\
\hline A & Ipitanga & $38^{\circ} 23^{\prime} 23^{\prime \prime}$ & $12^{\circ} 51^{\prime} 19^{\prime \prime}$ \\
B & Joanes I & $38^{\circ} 19^{\prime} 27.42^{\prime \prime}$ & $12^{\circ} 50^{\prime} 11.09^{\prime \prime}$ \\
C & Jacuípe & $38^{\circ} 16^{\prime} 54.60^{\prime \prime}$ & $12^{\circ} 37^{\prime} 47.00^{\prime \prime}$ \\
D & Jacuípe & $38^{\circ} 14^{\prime} 16^{\prime \prime}$ & $12^{\circ} 34^{\prime} 16^{\prime \prime}$ \\
E & Jacuípe & $38^{\circ} 10^{\prime} 6^{\prime \prime}$ & $12^{\circ} 32^{\prime} 53^{\prime \prime}$ \\
F & Joanes II & $38^{\circ} 25^{\prime} 10^{\prime \prime}$ & $12^{\circ} 40^{\prime} 2^{\prime \prime}$ \\
G & Joanes II & $38^{\circ} 23^{\prime} 22^{\prime \prime}$ & $12^{\circ} 39^{\prime} 50^{\prime \prime}$ \\
H & Paraguaçu & $39^{\circ} 3^{\prime} 0^{\prime \prime}$ & $12^{\circ} 25^{\prime} 45^{\prime \prime}$ \\
I & Paraguaçu & $39^{\circ} 11^{\prime} 1^{\prime \prime}$ & $12^{\circ} 30^{\prime} 12^{\prime \prime}$ \\
J & Paraguaçu & $39^{\circ} 15^{\prime} 51^{\prime \prime}$ & $12^{\circ} 32^{\prime} 29^{\prime \prime}$ \\
K & Paraguaçu & $39^{\circ} 1^{\prime} 48^{\prime \prime}$ & $12^{\circ} 32^{\prime} 12^{\prime \prime}$ \\
1 & Jacuípe & $39^{\circ} 0^{\prime} 3.85^{\prime \prime}$ & $12^{\circ} 17^{\prime} 8.30^{\prime \prime}$ \\
2 & Paraguaçu & $39^{\circ} 31^{\prime} 21.00^{\prime \prime}$ & $12^{\circ} 35^{\prime} 9.00^{\prime \prime} S$ \\
\hline
\end{tabular}




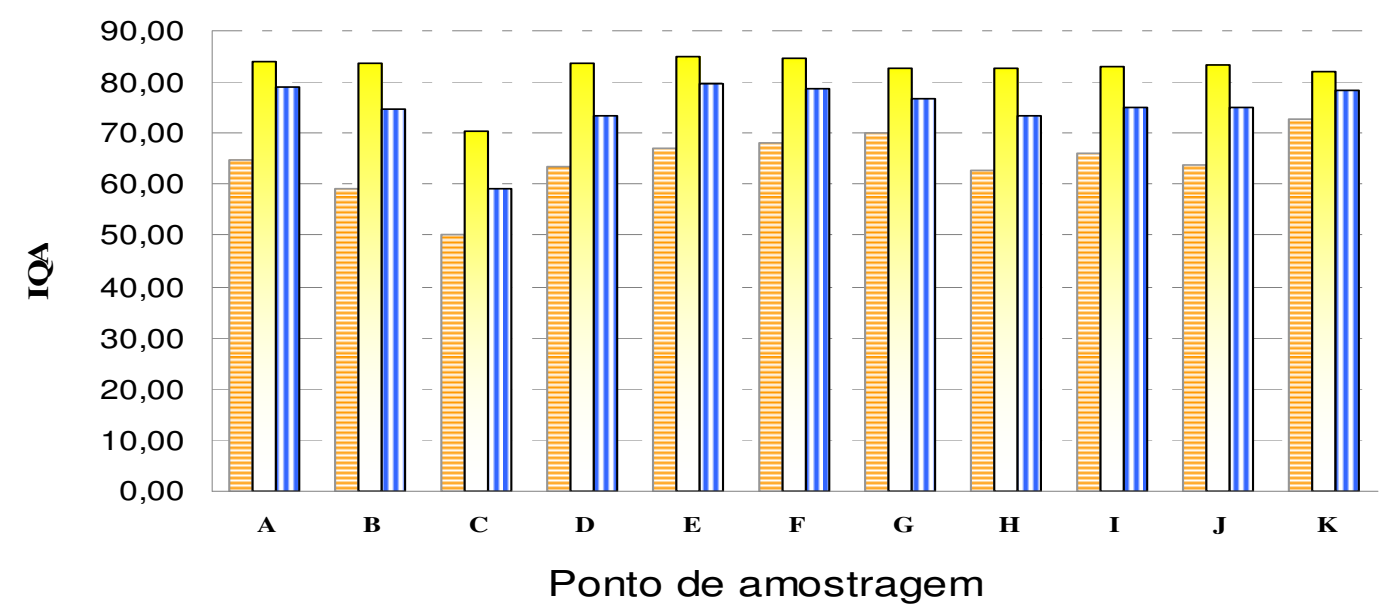

Mínimo $\square$ Máximo 皿 Médio

Figura 2.IQA nos pontos de amostragem das barragens.

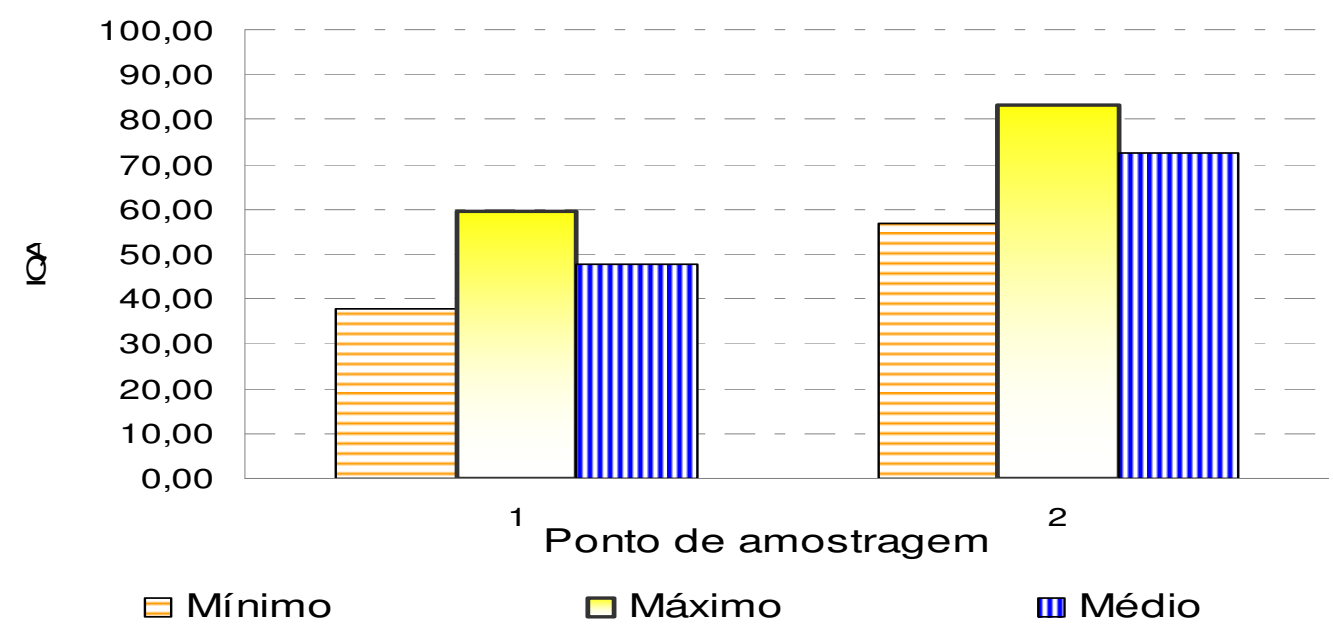

Figura 3.IQA nos pontos 1 e 2.

PERIÓDICO TCHÊ QUÍMICA • www.periodico.tchequimica.com • Vol. 14 N. 28.

• ISSN 1806-0374 (impresso) • ISSN 1806-9827 (CD-ROM) • ISSN 2179-0302 (meio eletrônico) (C) 2017. Porto Alegre, RS. Brasil 